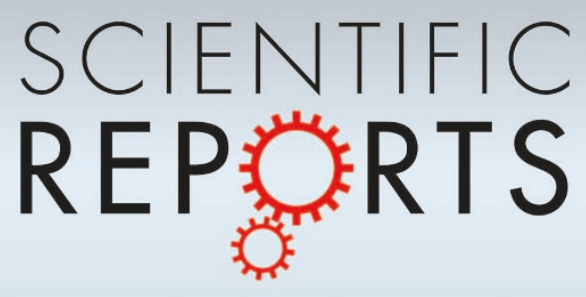

\title{
OPEN Low-temperature excess heat capacity in fresnoite glass and crystal
}

SUBJECT AREAS:

PHASE TRANSITIONS

AND CRITICAL

PHENOMENA

STRUCTURE OF SOLIDS AND

LIQUIDS

Received

1 April 2014

Accepted

12 September 2014

Published

6 October 2014

Correspondence and requests for materials should be addressed to

K.N. (k-nakamura@ laser.apph.tohoku.ac.

ip)

\author{
Kensaku Nakamura, Yoshihiro Takahashi \& Takumi Fujiwara \\ Department of Applied Physics, Tohoku University, 6-6-05 Aoba-ku, Sendai 980-8579, Japan.
}

The effect of thermal annealing on low-temperature excess heat capacity was investigated in fresnoite $\left(\mathrm{Ba}_{2} \mathrm{TiSi}_{2} \mathrm{O}_{8}\right)$ glass. The amplitudes of the excess heat capacity decreased, and their positions shifted to a higher temperature by relaxation or crystallization. In particular, we revealed that the change in the excess heat capacity during transition from the glassy state to the crystalline state is relatively small compared with that of other oxides. Therefore, it is suggested that distribution of the excess vibrational density of states of the glass is similar to that of the corresponding crystal.

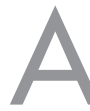

morphous materials have an excess vibrational density of states (VDOS), $g(\omega)$, over that predicted by the Debye theory in the terahertz frequency range. This excess VDOS manifests as a larger heat capacity $\left(C_{\mathrm{p}}\right)$ than the Debye $T^{3}$ law in the low-temperature region, and a hump, a so-called "boson peak," appears in the $C_{\mathrm{p}} / T^{3}-T$ plot ( $T$ : temperature in Kelvin $)^{1}$. The boson peak also appears as a broad band in the low-energy region of Raman/inelastic-neutron scattering spectra ${ }^{2,3}$, and is a universal feature in amorphous matter because the boson peak is obtained regardless of the components, e.g., inorganic, organic, and metal substances ${ }^{4-6}$. Although the boson peak is closely related to transverse acoustic phonons ${ }^{7-9}$, its origin is still debated and many theoretical and experimental studies have been conducted in order to elucidate the mechanism of the boson peak. Theoretical simulations have indicated that thermal history governs the boson-peak feature, e.g., the height and position $^{10,11}$. In addition, it has been experimentally found that thermal annealing decreases the boson-peak intensity in the low-temperature heat capacity of oxide, organic and metallic glasses ${ }^{5,12,13}$.

It is known that some crystals also show excess $C_{\mathrm{p}}$ in the low-temperature range similar to that of the boson peak in the $C_{\mathrm{p}} / T^{3}-T$ plot $^{4,14}$. The excess $C_{\mathrm{p}}$ of a crystal is associated with an increase in VDOS at the critical points, i.e., the so-called "van-Hove singularity," at which the Brillouin-zone boundary is situated in phonon disper$\operatorname{sion}^{4,14}$. In addition, the position of the excess VDOS at the van-Hove singularity shifts to a lower frequency when the force constant gets into a disorder ${ }^{8,9}$. According to Chumakov, the excess-DOS distribution of sodium iron silicate glass approaches that of the corresponding crystal phase as the glass is subjected to high-pressure conditions $s^{15}$. These studies encouraged us to consider the anomalous $C_{\mathrm{p}}$ behavior due to excess VDOS of the glassy state originating through a similar mechanism as that observed in the crystal state. Therefore, comparison between the boson peak in the glassy state, and the excess modes of its crystal-state counterpart, is a direct and decisive method of understanding the nature of the boson peak. Some studies have experimentally shown the comparison of the excess heat capacities between glass and its counterpart, and crystallization effect on the excess heat capacity in oxide, inorganic and metallic materials ${ }^{14-20}$. In terms of the oxide glass, although the crystal counterpart is often obtained through thermal crystallization in the parent glass ${ }^{15-17}$, the effect of annealing conditions on the excess $C_{\mathrm{p}}$ and/or VDOS have not been dealt with. Therefore, it is significant to employ an oxide glass, in which the crystal fraction is controllable, to elucidate the effect of crystallization on the excess heat capacity (VDOS). In this paper, we examine the effects of structural relaxation and subsequent crystallization processes, on low-temperature excess heat capacity by thermal annealing of a glass and discuss the relation of the excess $C_{p}$ between the glass and its crystal counterpart. We chose fresnoite $\left(\mathrm{Ba}_{2} \mathrm{TiSi}_{2} \mathrm{O}_{8}\right)$ glass for this study because the isochemical $\mathrm{Ba}_{2} \mathrm{TiSi}_{2} \mathrm{O}_{8}$ phase is crystallizable through homogenous nucleation ${ }^{21}$, and there is adequate knowledge concerning structural and physical properties of fresnoite-type $\mathrm{Ba}_{2} \mathrm{TiSi}_{2} \mathrm{O}_{8}$ crystal ${ }^{22,23}$. Thus, fresnoite glass/crystal is a suitable system in this study.

\section{Results}

Figure 1 shows the volume fraction of the $\mathrm{Ba}_{2} \mathrm{TiSi}_{2} \mathrm{O}_{8}$ crystal as a function of annealing temperature, which is obtained on the basis of TEM observation in the test samples. The fractions in the test samples at $1003 \mathrm{~K}$ and 


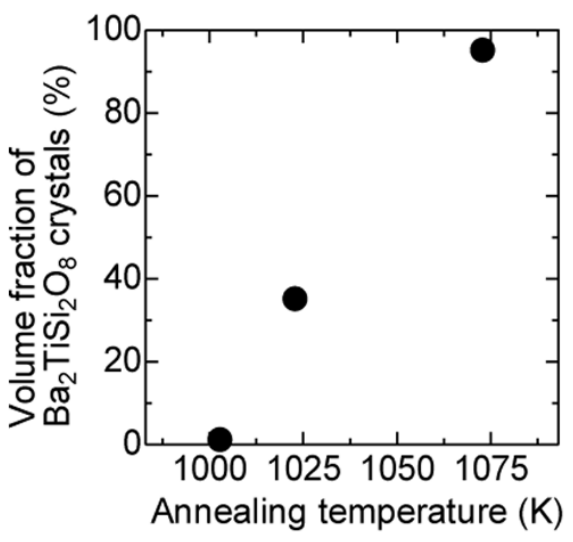

Figure 1 Relation between volume fraction of fresnoite phase and annealing temperature (annealing period of $1 \mathrm{~h}$ ). The fraction was estimated via TEM observation in samples.

$1023 \mathrm{~K}$ were estimated to be $\sim 1-2 \%$ and $\sim 35 \%$, respectively. The sample annealed at $1073 \mathrm{~K}$ consisted of an almost crystalline phase, i.e., $\sim 95 \%$ of $\mathrm{Ba}_{2} \mathrm{TiSi}_{2} \mathrm{O}_{8}$ crystal.

In Fig. 2, we show the heat capacities $\left(C_{\mathrm{p}}\right)$ as a function of temperature $(T)$ in the studied samples. Although the obtained data seem to be ordinary curves [Fig. 2(a)], the difference in $C_{\mathrm{p}}$ between the glassy and annealed samples, i.e., $\Delta C_{\mathrm{p}}$, exhibited a positive value in the region below $\sim 30 \mathrm{~K}$ [Fig. 2(b)]. The positive $\Delta C_{\mathrm{p}}$ indicates that the excess $C_{\mathrm{p}}$ of the glassy sample is larger than that of the annealed samples in this temperature range because this region is affected by the excess heat capacity beyond that corresponding the Debye $T^{3}$ law. However, above $\sim 30 \mathrm{~K}$, the $\Delta C_{\mathrm{p}}$ of the sample at $1003 \mathrm{~K}$ is positive, while that of samples at $1023 \mathrm{~K}$ and $1073 \mathrm{~K}$ are negative. It is known that over a few tens of $\mathrm{K}, C_{\mathrm{p}}$ of as-prepared glass tends to be larger than that of the annealed (relaxed) glasses ${ }^{24}$. Since the sample annealed at $1003 \mathrm{~K}$ was almost in the glassy state, as seen in Fig. 1, the decrease in $C_{\mathrm{p}}$ by annealing at $1003 \mathrm{~K}$, which gives the positive value of $\Delta C_{\mathrm{p}}$, is due to relaxation of the glassy phase. On the other hand, the samples at $1023 \mathrm{~K}$ and $1073 \mathrm{~K}$ involve the crystalline phase, and therefore the negative values of $\Delta C_{\mathrm{p}}$ strongly suggest that above $\sim 30 \mathrm{~K}, C_{\mathrm{p}}$ of the $\mathrm{Ba}_{2} \mathrm{TiSi}_{2} \mathrm{O}_{8}$ crystal is larger than that of the parent glass. According to Richet, in many silicate systems, the heat capacity difference between the glass and the corresponding crystal possess positive $\Delta C_{\mathrm{p}}$ values above $\sim 30 \mathrm{~K}$, whereas the $\mathrm{CaAl}_{2} \mathrm{Si}_{2} \mathrm{O}_{8}$ system has negative values ${ }^{25}$. Therefore, the $\Delta C_{\mathrm{p}}<0$ in $\mathrm{Ba}_{2} \mathrm{TiSi}_{2} \mathrm{O}_{8}$ is a rare case, similar to that in the $\mathrm{CaAl}_{2} \mathrm{Si}_{2} \mathrm{O}_{8}$ composition. Richet has also described that the degree of structural ordering of the crystalline phase is related to the value of $\Delta C_{\mathrm{p}}{ }^{25}$.

In Fig. 3, we show the $C_{\mathrm{p}} / T^{3}$ and $\Delta C_{\mathrm{p}} / T^{3}$ curves as functions of temperature in the studied samples. In all measured samples, broad peaks could be observed in the $C_{\mathrm{p}} / T^{3}-T$ plot around $10 \mathrm{~K}-20 \mathrm{~K}$ [Fig. 3(a)], and the intensity of these peaks decreased with the increase in the annealing temperature. In addition, below $4 \mathrm{~K}$, $\Delta C_{\mathrm{p}} / T^{3}$ increased as the temperature decreased [Fig. 3(b)]. Generally, the heat capacity of glass is attributed to by the two-level tunneling states, which appear at lower temperatures than bosonpeak contributions ${ }^{19,26}$. Therefore, the difference in $\Delta C_{\mathrm{p}} / T^{3}$ below $4 \mathrm{~K}$ by the annealing temperature might be related to the disappearance of the tunneling contribution in the glassy phases ${ }^{19}$.

\section{Discussion}

We noticed that $C_{\mathrm{p}} / T^{3}$ of the sample obtained at $1003 \mathrm{~K}$ was smaller than that of the as-prepared glass [Fig. 3(a)], indicating that $C_{\mathrm{p}} / T^{3}$ decreased via relaxation of the glassy phase by annealing at $1003 \mathrm{~K}$. Singh et al. have simulated the VDOS of glass based on the potential energy landscape theory and have suggested that the boson peak shifts to a higher frequency and decreases in height when the cooling rate is slower (from the liquid state) ${ }^{11}$. In other words, the boson peak of glass, in which the energy state is trapped at a deeper minimum in the landscape, shows a higher frequency and lower intensity. In this study, the as-prepared glass could have a higher energy than the sample annealed at $1003 \mathrm{~K}$ because the sample is adequately relaxed. Therefore, it is reasonable that the boson peak in the sample at $1003 \mathrm{~K}$ appears at a higher frequency and with a smaller intensity than the as-prepared glass. $C_{\mathrm{p}}$ is known to be expressed as

$$
C_{p}(T)=3 N k_{B} \int_{0}^{v_{D}} g(\omega)\left(\frac{\hbar \omega}{k_{B} T}\right)^{2} \frac{\exp \left(\frac{\hbar \omega}{k_{B} T}\right)}{\left[\exp \left(\frac{\hbar \omega}{k_{B} T}\right)-1\right]^{2}} d \omega,
$$

where $N$ is the number of atoms, $\hbar$ is Planck's constant, $k_{\mathrm{B}}$ is Boltzmann's constant, and $v_{\mathrm{D}}$ is the Debye frequency ${ }^{27}$. Taking Eq. (1) into account, one can see that the decrease in $C_{\mathrm{p}} / T^{3}$ is due to the reduction of excess $g(\omega)$ by annealing at $1003 \mathrm{~K}$, in accordance with the prediction obtained by the simulation ${ }^{11}$. The annealing (or thermal relaxation) effect on $C_{\mathrm{p}} / T^{3}$ is also confirmed in metallic and organic materials $s^{5,13}$.

In terms of $C_{\mathrm{p}} / T^{3}$, the values of the samples annealed at $1023 \mathrm{~K}$ and $1073 \mathrm{~K}$, in which crystalline $\mathrm{Ba}_{2} \mathrm{TiSi}_{2} \mathrm{O}_{8}$ is main the phase, were lower than those of the as-prepared precursor and sample annealed at $1003 \mathrm{~K}$, in which the glass is in the total/main phase [Fig. 3(a)]. According to Crupi et al., the low-temperature heat capacity mea- (a)

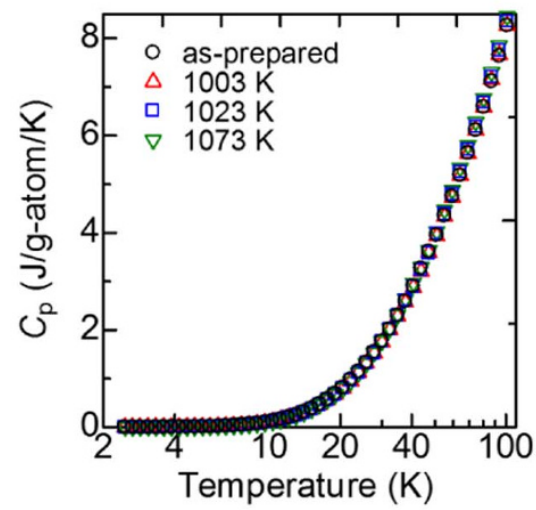

(b)

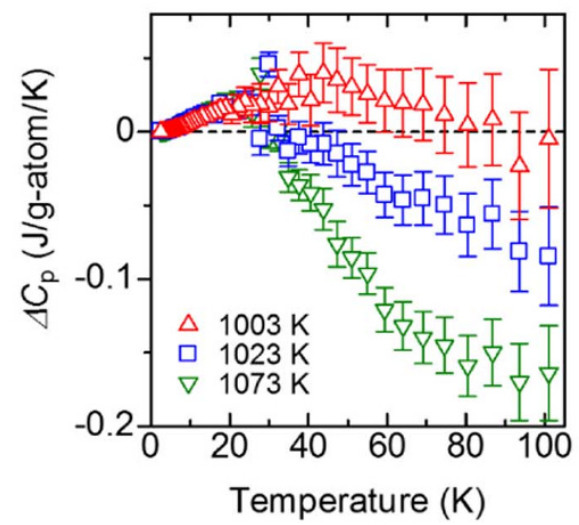

Figure $2 \mid$ Heat capacity $\left(C_{\mathrm{p}}\right)$ measurements in as-prepared and annealed glasses: (a) Measured $C_{\mathrm{p}}$ as a function of temperature (as-obtained data). (b) Difference in $C_{\mathrm{p}}$ between as-prepared and annealed samples, i.e., $\Delta C_{\mathrm{p}}$. 
(a)

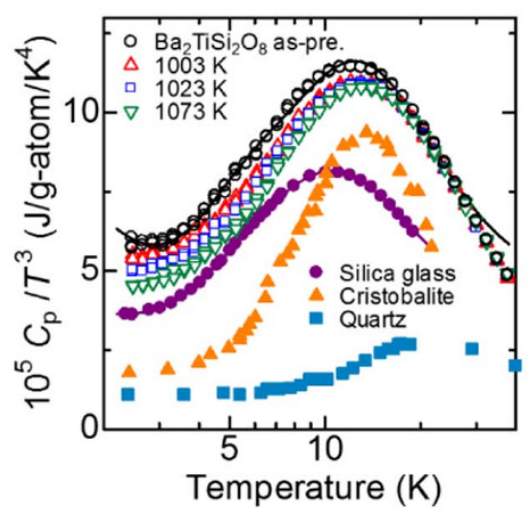

(b)

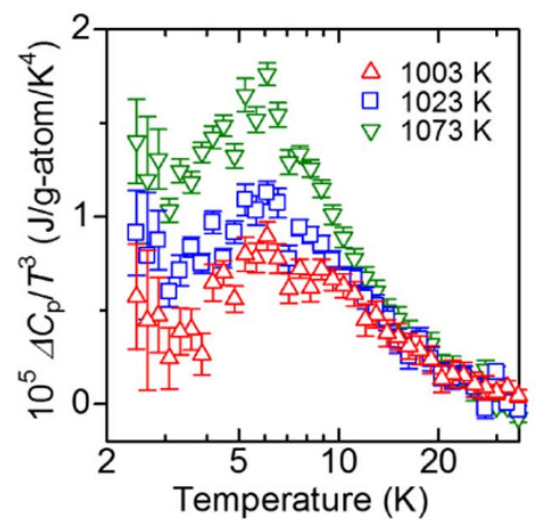

Figure 3 Heat capacity measurements in studied samples: (a) $C_{\mathrm{p}} / T^{3}$ versus temperature in fresnoite glass and annealed samples (open symbols).

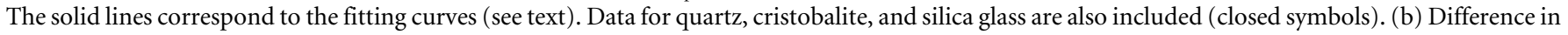
$C_{\mathrm{p}} / T^{3}$ between as-prepared glass and samples annealed at different temperatures, i.e., $\Delta C_{\mathrm{p}} / T^{3}$ as a function of temperature.

surement revealed that the boson-peak intensity in $\mathrm{CsB}_{3} \mathrm{O}_{5}$ glass is higher than the excess heat capacity in the $\mathrm{CsB}_{3} \mathrm{O}_{5}$ crystal ${ }^{16}$. In addition, Chumakov also demonstrated that the boson peak of the $\mathrm{Na}_{2} \mathrm{FeSi}_{3} \mathrm{O}_{8.5}$ glass has higher amplitude than the excess VDOS of its $\mathrm{NaFeSi}_{2} \mathrm{O}_{6}$ crystal counterpart ${ }^{15}$. Therefore, taking their reports into account, the results in this study are reasonable.

In Fig. 3(a), we include the data from $\mathrm{SiO}_{2}$ with different states, i.e., quartz and cristobalite (polymorphs) and silica glass to compare the $C_{\mathrm{p}} / T^{3}$ values between $\mathrm{SiO}_{2}$ and fresnoite samples. In Fig. 4, we show the relation between $\left(C_{\mathrm{p}} / T^{3}\right)_{\max }$ and $T_{\max }$ in these samples. The data from the $\mathrm{SiO}_{2}$ samples were cited from references ${ }^{18,28,29}$. Figs. 3(a) and 4 brings to our notice that the values of $C_{\mathrm{p}} / T^{3}$ in the $\mathrm{SiO}_{2}$ samples satisfy cristobalite $>$ glass $>$ quartz. Richet found that the difference in the $C_{\mathrm{p}} / T^{3}$ values between $\mathrm{SiO}_{2}$ glass and the cristobalite is considerably small compared with the difference between other glass-forming oxides $\left(\mathrm{B}_{2} \mathrm{O}_{3}\right.$ and $\left.\mathrm{GeO}_{2}\right)$ and their corresponding crystals ${ }^{18}$. In addition, it was found that when the difference in density between them is small, $C_{p} / T^{3}$ of the glass approaches that of the crystal. Relative-density differences between the $\mathrm{SiO}_{2}$ glass and quartz were determined to be $\sim 20 \%$, while the cristobalite was determined to be $\sim 6 \%{ }^{18}$. In stoichiometric $\mathrm{Ba}_{2} \mathrm{TiSi}_{2} \mathrm{O}_{8}$, the difference between the glass and crystal is $\sim 3.5 \%{ }^{30}$ and its value is smaller than those mentioned above. Chumakov et al. suggested that the excess VDOS of the $\mathrm{Na}_{2} \mathrm{FeSi}_{3} \mathrm{O}_{8.5}$ glass (density: $2.714 \mathrm{~g} / \mathrm{cm}^{3}$ ) approached that of the $\mathrm{NaFeSi}_{2} \mathrm{O}_{6}$ crystal counterpart (density $3.631 \mathrm{~g} / \mathrm{cm}^{3}$ ) via high-pressure densification, suggesting that the boson peak also appears in other similar phenomena, which is seen in the crystal state, i.e., piling up of the acoustic states at the Brillouin-zone boundary ${ }^{15}$. Taking the

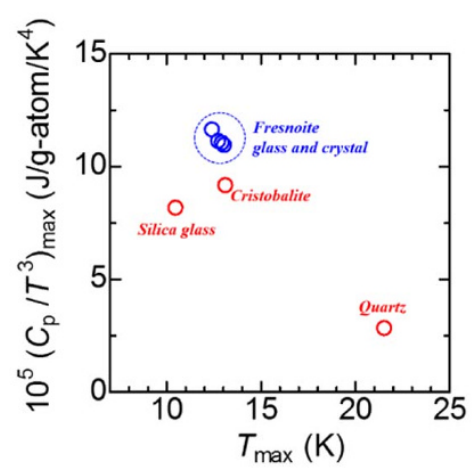

Figure $4 \mid$ Relation between $\left(C_{\mathrm{p}} / T^{3}\right)_{\max }$ and $T_{\max }$ in glassy and crystalline states for fresnoite $\left(\mathrm{Ba}_{2} \mathrm{TiSi}_{2} \mathrm{O}_{8}\right)$ and silica $\left(\mathrm{SiO}_{2}\right)$. descriptions into account, the results in this study strongly suggest that if the difference in density between the glass and crystal is small, the difference in the excess $C_{\mathrm{p}}$ (or VDOS) is also small. Furthermore, we found considerable similarity in not only $C_{\mathrm{p}} / T^{3}$ but also $T_{\max }$ between the glass and crystal in fresnoite composition (Fig. 4). Since $C_{\mathrm{p}}$ is expressed as an integration of $g(\omega)$, according to Eq. (1), the similarity of excess $C_{p}$ between the glass and crystal does not necessarily mean that the same is true for distribution of $g(\omega)$. However, Safarik experimentally reveals that the $T_{\max }$ values are associated with the Brillouin-zone boundary frequency in metallic systems ${ }^{14}$. In oxide systems, the compositional dependence of $\left(C_{\mathrm{p}}\right)$ $\left.T^{3}\right)_{\max }$ and $T_{\max }$ is consistent with the dependence of the intensity and position for the excess $\operatorname{VDOS}^{31}$. Furthermore, very recently, it is demonstrated that the $\mathrm{SiO}_{2}$ glass and $\mathrm{SiO}_{2}$ polymorph, which has a similar density to the glass, have the same number of the excess state in VDOS and show the same heat capacity ${ }^{32}$.These studies indicate that the analysis of excess $C_{\mathrm{p}}$ is helpful for understanding excess VDOS. Since the comparison between the glassy fresnoite and its corresponding crystal indicated that the minimum change in $C_{\mathrm{p}} / T^{3}$ and $T_{\max }$ is due to glass-crystal transformation, it is reasonable to conclude that the excess-VDOS distribution of the glass closely resembles that of the crystal.

In summary, we measured the low-temperature heat capacity of the as-prepared, relaxed, and fresnoite-crystallized glasses, which have a stoichiometric fresnoite $\left(\mathrm{Ba}_{2} \mathrm{TiSi}_{2} \mathrm{O}_{8}\right)$ composition. The $C_{\mathrm{p}} /$ $T^{3}-T$ plot revealed a broad peak around $10 \mathrm{~K}-20 \mathrm{~K}$, corresponding to excess heat capacity. Particularly, the relaxed/crystallized samples possessed a lower value of $C_{\mathrm{p}} / T^{3}$ and higher maximum position situated at a high temperature, compared with the as-prepared sample. Furthermore, although the as-prepared glass undergoes a drastic structural transformation after crystallization, i.e., a glass-crystal transition, $C_{\mathrm{p}} / T^{3}$ of the crystallized sample was almost identical to that of the relaxed sample. This strongly suggests that the distribution of excess VDOS of the glassy fresnoite is considerably similar to that of the crystalline $\mathrm{Ba}_{2} \mathrm{TiSi}_{2} \mathrm{O}_{8}$. Therefore, comparison of excess heat capacity (or VDOS) in fresnoite glass and crystal, which have same composition (stoichiometry), can be useful to understand the origin of boson peak.

\section{Methods}

Test sample preparation. $\mathrm{Ba}_{2} \mathrm{TiSi}_{2} \mathrm{O}_{8}$ glass, i.e., the glassy state of stoichiometric fresnoite phase, was synthesized by a conventional melt-quenching method. The synthesis was processed at $1723 \mathrm{~K}$ using a platinum crucible, and finally we acquired the transparent and colorless glassy sample having a glass-transition temperature $T_{\mathrm{g}} \sim 990 \mathrm{~K}$, which is estimated through differential thermal analysis (heating rare: $10 \mathrm{~K} / \mathrm{min}$ ). Test samples were obtained via annealing the glass at $1003 \mathrm{~K}, 1023 \mathrm{~K}$, and 
$1073 \mathrm{~K}$ for $1 \mathrm{~h}$. The $\mathrm{x}$-ray diffraction analysis in the as-prepared glass and sample annealed at $1003 \mathrm{~K}$ showed a halo pattern, indicating the amorphous state. On the other hand, sharp diffraction peaks due to the formation of $\mathrm{Ba}_{2} \mathrm{TiSi}_{2} \mathrm{O}_{8}$ crystals were confirmed in the samples at $1023 \mathrm{~K}$ and $1073 \mathrm{~K}$.

Characterizations. We also conducted transmission electron microscopy (TEM) to evaluate crystal fractions for each sample. Low-temperature heat capacity measurements were performed via a relaxation method using a physical properties measurement system (Quantum Design Inc.). The obtained data were plotted as a function of temperature, i.e., a $C_{\mathrm{p}} / T^{3}-T$ plot and then were analyzed by the sum of a Debye contribution and Einstein modes to evaluate the maximum $\left(C_{\mathrm{p}} / T^{3}\right)_{\max }$ and its position $T_{\max }{ }^{16,33,34}$. For evaluation of the measured samples, we additionally took a quantum tunneling term into account ${ }^{16,19,26}$.

1. Pohl, R. O. [Low Temperature Specific Heat of Glasses]. Amorphous Solids: LowTemperature Properties [Phillips, W. A. (ed.)] [27-52], (Springer Verlag, New York, 1981).

2. Malinovsky, V. K. \& Sokolov, A. P. The nature of boson peak in Raman scattering in Glasses. Solid State Comm. 57, 757-761 (1986).

3. Sokolov, A. P., Buchenau, U., Steffen, W., Frick, B. \& Wischnewski, A. Comparison of Raman- and neutron-scattering data for glass-forming systems. Phys. Rev. B 52, 9815-9818 (1995)

4. Liu, X. \& Löhneysen, H. V. Specific-heat anomaly of amorphous solids at intermediate temperature (1 to $30 \mathrm{~K}$ ). Europhys. Lett. 33, 617-622 (1996).

5. Li, Y. Yu, P. \& Bai, H. Y. Study on the boson peak in bulk metallic glasses. J. Appl. Phys. 104, 013520-113526 (2008).

6. Hassaine, M. et al. Low-temperature thermal and elastoacoustic properties of butanol glasses: Study of position isomerism effects around the boson peak. Phys. Rev. B 85, 104206-104216 (2012).

7. Shintani, H. \& Tanaka, H. Universal link between the boson peak and transverse phonons in glass. Nature Mater. 7, 870-877 (2008).

8. Schirmacher, W., Diezemann, G. \& Ganter, C. Harmonic vibrational excitations in disordered solids and the "boson peak" Phys. Rev. Lett. 81, 136-139 (1998).

9. Taraskin, S. N., Loh, Y. L., Natarajan, G. \& Elliott, S. R. Origin of the boson peak in system with lattice disorder. Phys. Rev. Lett. 86, 1255-1258 (2001).

10. Grigera, T. S., Mayor, V. M., Parisi, G. \& Verrocchio, P. Phonon interpretation of the 'boson peak' in supercooled liquids. Nature 422, 289-292 (2003).

11. Singh, S., Ediger, M. D. \& Pablo, J. J. Ultrastable glasses from in silico vapor deposition. Nature Mater. 12, 139-144 (2013).

12. Champagnon, B., Chemarin, C. \& Richet, P. Fictive temperature and medium range order in silicate glasses: a relationship between heat capacity and boson peak. Philos. Mag. B 77, 663-669 (1998).

13. Castañeda, T. P., Riobóo, R. J. J. \& Ramos, M. A. Two-level systems and boson peak remain stable in 110-million-year-old amber glass. Phys. Rev. Lett. 112, 165901-165905 (2014).

14. Safarik, D. J., Schwarz, R. B. \& Hundley, M. F. Similarities in the $C_{p} / T^{3}$ peaks in amorphous and crystalline metals. Phys. Rev. Lett. 96, 195902-195905 (2006).

15. Chumakov, A. I. et al. Equivalence of the boson peak in glasses to the transverse acoustic van Hove singularity in crystals. Phys. Rev. Lett. 106, 225501-225505 (2011).

16. Crupi, C., Angelo, G. D. \& Vasi, C. Low-energy vibrational dynamics of cesium borate glasses. J. Phys. Chem. B 116, 6499-6505 (2012).

17. Carini, G. et al. Influence of packing on low energy vibrations of densified glasses. Phys. Rev. Lett. 111, 245502-245506 (2013).

18. Richet, P., Lingny, D. \& Westrum Jr, E. F. Low-temperature heat capacity of $\mathrm{GeO}_{2}$ and $\mathrm{B}_{2} \mathrm{O}_{3}$ glasses: thermophysical and structural implications. J. Non-Cryst. Solids 315, 20-30 (2003).

19. Talón, C., Ramos, M. A. \& Vieira, S. Low-temperature specific heat of amorphous, orientational glass, and crystal, and crystal phases of ethanol. Phys. Rev. B 66, 012201-012204 (2002)

20. Vasiliev, A. N. et al. Relationship between low-temperature boson heat capacity and high-temperature shear modulus relaxation in a metallic glass. Phys. Rev. B 80, 172102-172105 (2009).
21. Cabral, A. A., Fokin, V. M., Zanotto, E. D. \& Chinaglia, C. R. Nanocrystallization of fresnoite glass. I. Nucleation and growth kinetics. J. Non-Cryst. Solids 330 , 174-186 (2003)

22. Robert, M. G. \& Tarte, P. Vibrational spectrum of fresnoite $\left(\mathrm{Ba}_{2} \mathrm{TiOSi}_{2} \mathrm{O}_{7}\right)$ and isostructural compounds. Phys. Chem. Minerals 7, 26-30 (1981)

23. Markgraf, S. A., Halliyal, A., Bhalla, A. S., Newnham, R. E. \& Prewitt, C. T. X-ray structure refinement and pyroelectric investigation of fresnoite, $\mathrm{Ba}_{2} \mathrm{TiSi}_{2} \mathrm{O}_{8}$. Ferroelectrics 62, 17-26 (1985).

24. Richet, P., Robie, R. A. \& Hemingway, B. A. Low-temperature heat capacity of diopside glass $\left(\mathrm{CaMgSi}_{2} \mathrm{O}_{6}\right)$ : A calorimetric test of the configurational-entropy theory applied to the viscosity of liquid silicates. Geochim. Cosmochim. Acta $\mathbf{5 0}$ 1521-1533 (1986).

25. Richet, P., Robie, R. A. \& Hemingway, B. A. Entropy and structure of silicate glasses and melts. Geochim. Cosmochim. Acta 57, 2751-2766 (1993).

26. Phillips, W. A. Tunneling states in amorphous solids. J. Low Temp. Phys. 7, 351-360 (1972)

27. Sokolov, A. P., Kisliuk, A., Quitmann, D. \& Duval, E. Evaluation of density of vibrational states of glasses from low-frequency Raman spectra. Phys. Rev. B 48, 7692-7695 (1993).

28. Flubacher, P., Leadbetter, A. J., Morrison, J. A. \& Stoicheff, B. P. The lowtemperature heat capacity and the Raman and Brillouin spectra of vitreous silica. J. Phys. Chem. Solids 12, 53-65 (1959).

29. Bilir, N. \& Phillips, W. A. Phonons in $\mathrm{SiO}_{2}$ : the low-temperature heat capacity of cristobalite. Philos. Mag. 32, 113-122 (1975)

30. Shinozaki, K., Honma, T. \& Komastu, T. Elastic properties and Vickers hardness of optically transparent glass-ceramics with fresnoite $\mathrm{Ba}_{2} \mathrm{TiSi}_{2} \mathrm{O}_{8}$ nanocrystals Mater. Res. Bull. 46, 922-928 (2011).

31. Angelo, G. D. et al. Boson peak in alkaline borate glasses: Raman spectroscopy, neutron scattering, and specific-heat measurements. Phys. Rev. B 79 014206-014214 (2009).

32. Chumakov, A. I. et al. Role of Disorder in the Thermodynamics and Atomic Dynamics of Glasses. Phys. Rev, Lett. 112, 025502-025507 (2014).

33. Zhou, Z. et al. On the existence of Einstein oscillators and thermal conductivity in bulk metallic glass. Appl. Phys. Lett. 89, 031924-031926 (2006).

34. Melot, B. C. et al. Large low-temperature specific heat in pyrochlore $\mathrm{Bi}_{2} \mathrm{Ti}_{2} \mathrm{O}_{7}$. Phys. Rev. B 79, 224111-224115 (2009).

\section{Acknowledgments}

This work was supported by the Ministry of Education, Culture, Sports, Science and Technology (MEXT) of the Japanese government. The authors would like to thank Prof. Tadashi Adachi of Faculty of Science and Technology, Sophia University, and Dr. Takamichi Miyazaki of Department of Instrumental Analysis, School of Engineering, Tohoku University for significant contributions to this study.

\section{Author contributions}

Y.T. and T.F. designed the study. K.N. performed experiments to characterize the test samples, and performed the analyses. K.N., Y.T. and T.F. wrote the paper.

\section{Additional information}

Competing financial interests: The authors declare no competing financial interests.

How to cite this article: Nakamura, K., Takahashi, Y. \& Fujiwara, T. Low-temperature excess heat capacity in fresnoite glass and crystal. Sci. Rep. 4, 6523; DOI:10.1038/srep06523 (2014)

This work is licensed under a Creative Commons Attribution-NonCommercialNoDerivs 4.0 International License. The images or other third party material in this article are included in the article's Creative Commons license, unless indicated otherwise in the credit line; if the material is not included under the Creative Commons license, users will need to obtain permission from the license holder in order to reproduce the material. To view a copy of this license, visit http:// creativecommons.org/licenses/by-nc-nd/4.0/ 